\title{
Crise da escola ou na escola? Uma análise da crise de sentido dos sistemas públicos de escolarização obrigatória
}

\author{
Geraldo Barroso \\ Universidade Federal de Pernambuco, Brasil
}

\section{Resumo}

Este estudo coloca em discussão os significados que são atribuídos à crise da escola pública de frequência obrigatória na literatura educacional crítica produzida desde fins do século XX no Brasil e em Portugal. Elenca as expectativas otimistas que impulsionaram — após a Segunda Guerra Mundial - a massificação da instituição escolar, fazendo um confronto com os impasses com que os sistemas públicos de ensino se defrontam, neste início do século XXI, diante das promessas não cumpridas da modernidade. Aborda, ainda, o impacto das transformações de economias e culturas globalizadas, de sociedades multiculturais, de informatização acelerada e de Estados-Nação esvaziados de suas funções históricas para a configuração dessa crise e os diferentes dispositivos que têm sido elaborados, no Brasil e em Portugal, destinados a superá-la.

Palavras-chave

Ensino público; Fracasso escolar; História da educação; Escola pública

\section{Apresentação}

O centro das preocupações deste texto ${ }^{1}$ é aquilo que recebe a denominação comum de 'crise da escola', particularmente - entre as inumeráveis crises que, há mais de um século, são atribuídas à instituição escolar - aquela que, desde o final do século $X X$, tem sido registrada por 
inúmeros autores ${ }^{2}$ e que atinge os Sistemas Públicos de Ensino (que daqui por diante serão indicados como SPE).

Desde os anos 1960, quando estudante da escola secundária, as expressões 'a educação está em crise' ou 'a escola vive uma crise' eram banais. Durante toda década de 1970 - que correspondeu ao curso de licenciatura e ao início de nossa trajetória como profissional docente -, eis a insistente 'crise da educação' nos acompanhando. Durante a década de 1980, época de lutas e esperanças intensas pelo fim da ditadura militar no Brasil, a superação da "crise da educação pública" nos impulsionava contra inimigos reais e imaginários. E entramos pelos anos $1990 \mathrm{com}$ a sonoridade desse insistente vocábulo a acompanhar as nossas vidas.

Se essas expressões fossem submetidas a uma arqueologia minuciosa, não deveria ser difícil constatar que se trata, sempre, de uma crise da mesma escola, secular, elitista, seletiva, meritocrática; contestada e desejada, rejeitada e imprescindível. Sempre as mesmas insatisfações e sempre as mesmas crenças sobre a necessidade de transformá-la. A crise da escola, para as consciências progressistas, residia no seu anacronismo, no seu apêgo ao passado. Para os conservadores, a crise era produto da sua massificação, da presença nos bancos escolares de uma população culturalmente despreparada para frequentá-la e cumprir as suas exigências. Para uma esquerda ortodoxa, a crise era intrínseca à escola burguesa, reprodutora de desigualdades sociais e inculcadora de ideologias estranhas aos "interesses históricos" dos trabalhadores. Cada qual punha seus óculos para enxergar a "crise da escola".

Em meio a essas diferentes percepções, constatava-se que a crise da escola deixava de ser um problema nacional, localizado, registrando-se simultaneamente em diferentes países do mundo, sempre com uma enorme semelhança de elementos (Casassus, 1995; Tedesco, 1998; Sacristán, 1999; Cortesão, 2000; Goméz, 2001; Vorraber, 2003; Enguita, 2004, entre outros). Essa 'internacionalização' da crise da instituição escolar e/ou dos sistemas públicos de ensino vem associada ao esgotamento do chamado projeto da modernidade e à sua impossibilidade de cumprir as promessas implícitas que justificaram o acesso irrestrito e indistinto (e, em alguns casos, compulsório) das populações submetidas à autoridade dos Estados Nacionais às instituições escolares. Num mundo cada vez mais parecido, as crises não haviam de ser diferentes... 
O termo 'crise' surge neste texto frequentemente sob aspas e isto se faz para ressaltar o seu caráter polissêmico e necessariamente contextualizado. A crise a que nos referimos não tem uma natureza objetiva/evidenciável e que se apresente a todo observador como um objeto único, com a mesma constituição. A apontada crise dos sistemas educativos não reside em um lugar único, claramente visível, à espera de ser descrita 'tal como é'. Trata-se de uma construção, uma produção de olhares que se debruçam sobre a educação pública e elegem, no conjunto complexo sobre a qual ela está fundada, 'alvos' que expressam desejos e intenções relativos àquilo que a educação escolar não é e deveria ser. É, portanto, um campo aberto a disputas em torno de seus sentidos.

Na mesma direção, entendemos que o exercício da investigação sobre o significado atribuído à 'crise da escola' não pode ficar restrito a ela própria, posto que é possível pensá-la enquanto uma crise da educação ou dos processos educativos societais (e a escola, aqui, seria apenas um dos lugares institucionais onde pode ser registrada), de uma crise originada ou constituída fora dos seus contextos sociais ou cognitivos internos, mas que a atingem de maneira fulminante. É o caso dos efeitos da globalização econômica e cultural, das mudanças sensíveis nos sistemas produtivos e no papel dos Estados-Nação e, principalmente, da expansão das tecnologias da informação.

Igualmente não é possível limitar a investigação dessa mais recente crise da escola à sua temporalidade mais imediata e visível, as décadas finais do século $\mathrm{XX}$, momento em que a literatura crítica, em caráter planetário, a enfatiza. Daí a necessária recorrência à história da educação, na busca dos fatores/raízes que auxiliem dimensionar a sua ocorrência contemporânea, na perspectiva daquilo que Hobsbawm (1998) chama de história do tempo presente.

Entra em questão, nessa discussão, o empenho dos educadores que um dia acreditaram no projeto utópico de uma escola pública transformada e transformadora e que, hoje, não se recusam a pensar sobre a sua crise, mas que carregam a responsabilidade com as 'multidões' que foram chamadas às escolas e que se acham, como vítimas, inteiramente envolvidas na sua crise de sentido (Correia \& Matos, 2001; Cortesão, 2000; Vasconcelos, 2001). 
Às crianças que são levadas compulsoriamente às escolas parece ser mais fácil enganar com atividades. Mas todos nos encontramos em busca do que dizer aos jovens (pelo menos àqueles que conseguem incorporar uma escolaridade um pouco mais prolongada, cumprindo as etapas superiores do ensino básico) que são envolvidos por discursos repletos de promessas de que uma escolarização mais ampliada possibilita o acesso às necessárias recompensas sociais que são associadas - e não apenas pelo imaginário popular - à educação escolar e que questionam, de maneira cada vez mais incisiva e, às vezes, violenta, o sentido da escola. Buscamos o que dizer aos pais - notadamente aqueles pertencentes às camadas populares - que foram insistentemente convocados a participar na educação dos seus filhos, mas que se encontram atônitos porque percebem, mesmo que difusamente, que a escola não pode cumprir as promessas de transformar suas vidas, garantindo-lhes um futuro 'melhor'.

E o que podemos dizer aos professores, os principais responsáveis, em última análise, por realizar - ou não - os diferentes e sucessivos projetos de reforma das escolas? Diante da crise de sentido que envolve o ensino público, qual o significado de dirigir-se todos os dias da semana, todas as semanas de todos os meses, e por meses a fio, ao longo de anos e anos, às escolas e deparar-se cotidianamente com expressões - algumas profundamente angustiantes - dessa crise de sentido? Onde e como buscar impulsos motivadores e significados para estar todos os dias diante de seus alunos? Produzir, sobre eles ou com eles, o quê exatamente? Prometer-Ihes de um futuro transformado para si próprios e para a sociedade ou a 'nação'? Estimulá-los com melhores e mais promissores empregos? Falar-lhes das possibilidades de uma inserção política qualificada? Afinal, o que a instituição escolar universalizada assegura às novas gerações que são obrigadas a frequentá-la?

Estas são algumas das questões que nos incomodam e impulsionam. Elas são postas aqui para dimensionar a extensão e complexidade da tarefa atribuída às consciências críticas que elegeram a educação escolar como seu campo de atuação, profissional e militante. Esse incômodo é crescente porque, apesar dos repetidos anúncios de fim dos tempos modernos e seus projetos utópicos e das expressões repetidas de desencanto com a escola, as populações continuam a ser convencidas da necessidade inquestionável de 
submeter seus filhos a uma escolarização ampliada e se continua a nela ingressar de maneira crescente. Esse paradoxo é por si, se não houvessem outras razões, fator suficiente para justificar nosso envolvimento com essa temática.

\section{Os impasses da escola de massas}

A crise dos Sistemas Públicos de Ensino, insistentemente apontada desde as últimas décadas do século XX, está intimamente relacionada com a democratização do acesso à sua universalização. Rigorosamente, em respeito à crônica das crises contemporâneas da escola, deve-se lembrar que a sua insuficiência - ou o déficit de oferta - foi, durante a maior parte do século XX, o motivo das manifestações mais indignadas das consciências esclarecidas envolvidas com os projetos de mudança social e que apostavam na difusão da escola pública para realizá-los.

Ao mesmo tempo em que se indignavam com a escassez da oferta de ensino público, os setores sociais envolvidos com os projetos nacionais de 'modernização' e 'desenvolvimento' apontavam a discrepância entre estes projetos e o modelo escolar dominante, notadamente diante das características do nível mais sofisticado da educação básica, a escola secundária, alvo preferencial das críticas contundentes dos educadores comprometidos com o projeto de democratização da sociedade e que apostavam na ampliação das oportunidades educacionais como um fator estratégico para a sua efetivação. A escola secundária era acusada de ser exageradamente meritocrática e centrada na transmissão de conteúdos que a distanciavam da desejada modernização urbano-industrial. O caráter 'autoritário', 'anacrônico', 'verbalista', 'bacharelesco', 'livresco' (apenas para citar alguns dos muitos e pouco elogiativos adjetivos presentes na literatura da época) atribuído à escola secundária, pelo menos até aos anos 1960, caracterizava uma crise de legitimidade de uma escola pública muito pouco acessível e sem identidade com um projeto de transformação social imaginado por educadores 'esclarecidos' 3 e que deveria beneficiar a maioria da população.

Para estes setores, o alargamento da base social da escola pública era a maior prioridade ${ }^{4}$. E embora guardassem inúmeras críticas à forma histórica 
como aquela escola se organizava, ao caráter seletivo e elitista das - poucas - escolas públicas de então, essas críticas não eram suficientes para, nas décadas de euforia com o 'desenvolvimentismo'5, frear o imaginário popular que almejava ter acesso exatamente àquela escola, pois aquilo que parecia mais atraente nessa escola tão criticada e que, paradoxalmente, agregava apoio social crescente ao projeto de sua expansão, era exatamente o seu caráter distintivo (Spósito,1984).

A escola pública que alimentava o imaginário social desses anos apesar das críticas ácidas ao seu formato cultural, ao seu desenho curricular e às suas práticas didáticas - era exatamente aquela, tão criticada, que era adequada a um tipo de clientela que, por suas condições sócio-econômicas e capital cultural, apresentava menor dificuldade para enfrentar os inúmeros desafios postos por este modelo escolar. Era exatamente essa escola, cujo destino social dos seus frequentadores, com as exceções que sempre confirmam as regras, estava, de certa forma, pré-figurado e que parecia mais adequada a uma sociedade rigidamente hierarquizada do que a uma projetada sociedade urbano-industrial, democrática, aberta, era essa escola, insistimos, que se constituía no objeto de desejo da maioria da população que almejava para seus filhos uma escolarização mais prolongada 6 .

Dessa forma, por estranho que possa parecer, o alargamento da base social da escola pública (ou a sua transformação de uma instituição de elite em 'escola de massa'), apesar de insistentemente reclamada pelos setores progressistas comprometidos com ideais de justiça social, irá se deparar, de imediato, com uma escola organizada secularmente segundo uma lógica da padronização, de uniformização cultural (ou 'daltônica', segundo a expressão de Stoer) e, principalmente, extremamente ciosa de seu rigor avaliativo; uma escola que permanecia fiel à sua missão histórica de formação das elites vocacionadas para o exercício das funções intelectuais; adequada, portanto, aos setores sociais privilegiados/minoritários a que historicamente sempre servira.

Assim, a luta vitoriosa pela superação de uma das crises da escola a escassez da sua oferta - irá engendrar um outro fator de crise: a dificuldade da instituição escolar, tal como ela era 'formatada', de superar seu caráter seletivo excludente, voltada em todos os sentidos para promover, sempre, uma minoria 'qualificada' e excluir, como um processo naturalizado, 
uma maioria de 'incapazes'. As diferenças de condição sócio-econômica e de valores culturais dos novos grupos sociais, que passarão, crescentemente, a frequentá-la, não era objeto de consideração; o tratamento indistinto dispensado a todos era o de alunos, que continuavam a ser classificados como 'vocacionados' ou 'inaptos' para a progressão (ou não) pelas diferentes etapas dos sistemas de ensino.

Cabe, aqui, recordar que os SPE carregavam, desde o início de sua existência, a intencionalidade da 'unidade nacional', que se expressava sob a forma de um currículo único, assegurado pelo Estado, o único ente com poder e legitimidade social suficiente para assegurar o respeito ao princípio da igualdade de oportunidades de acesso aos bens cognitivos e, principalmente, poder legitimado para definir a sua universalidade, acima dos particularismos e interesses privados. O patrimônio cultural a ser difundido pelas escolas, presumia-se, destinava-se a ser integrado, de uma forma cumulativa, à bagagem cognitiva que os indivíduos deveriam transportar ao longo da vida (Correia, 2006), servindo como 'cimento' para uma integração estável à vida social (Sacristán, 1999).

A escola pública deveria ser igual para todos, laica, neutra e governada desde um centro supervisor que deveria garantir a equidade de todas as unidades entre si. Os docentes, selecionados por critérios meritocráticos, deveriam gozar de autonomia limitada para dar tratamento didático a conteúdos previamente definidos e, em função do desempenho cognitivo (e comportamental) dos alunos, definir os critérios de classificação/seleção que as escolas estavam autorizadas a fazer. A escola pública obrigatória antecedia a vida ativa dos adultos, avançando sobre o mundo familiar e comunitário, segregando as crianças e ensinando-lhes as regras de convivência social e de integração cultural que, pela sua especificidade (mesmo que possam, eventualmente, ser acusadas de parecer-se com prisões e hospícios), estavam fundadas na lógica da cognição, lógica que presidia às classificações atribuídas (capaz/incapaz, burro/inteligente, etc.) que iriam servir de referência para nortear a ocupação de lugares sociais distintos pelos futuros indivíduos adultos.

O pleno exercício dessa função seletiva abrigava-se sob a arquitetura de um imaginário social otimista, apostando-se na escola pública como instrumento capaz de promover o 'nivelamento das desigualdades de origem', 
de exercer uma função 'disciplinadora' e de distribuir 'capital cultural' indistintamente a todos (Sacristán, 2001: 19), reproduzindo esperanças continuamente renovadas de construção de um futuro diferenciado, promissor, para os indivíduos e sociedades, com maior 'bem-estar e plenitude' (Sacristán, 2001: 23). Não havia como suspeitar, mesmo que levemente, das possibilidades otimistas desta missão atribuída à educação escolar (Sacristán, 2001: 48-49). Difundia-se que o domínio da leitura, cálculo e escrita possibilitava o acesso a um tipo de conhecimento (sistemático) que, por sua vez, alargava os horizontes de utilização da ciência, da técnica e de novas formas e estrutura de pensamento e conhecimentos para benefício do progresso social. Esse patrimônio cultural apropriado pelos indivíduos qualificaria a eles próprios, a sociedade e a democracia.

O currículo 'nacional' sinalizava a impossibilidade de contemplar ou expressar identidades culturais diversas ou específicas, eventualmente manifestas no interior do corpo social. Os particularismos, as diversidades, as demandas locais era vistas como expressões minoritárias (logo irrelevantes) que poderiam provocar fissuras em um sistema que, para ser eficaz e efetivamente democrático, deveria oportunizar a todos, independentemente de etnia, gênero, classe, tradição cultural ou região geográfica, o mesmo ensino, os mesmos conteúdos. O monoculturalismo associado ao estadocentrismo fazia com que o plural/distinto/específico presente nas comunidades que freqüentavam as escolas públicas fosse anulado ou, no mínimo, hierarquizado e desqualificado diante dos saberes 'universais' que Ihe cabia difundir.

Assim, para as novas gerações às quais era imposta a freqüencia aos SPE, a escola não significava, apenas, um espaço de convívio e aprendizado das regras sociais dominantes, mas de assimilação de conteúdos. Das crianças e jovens que eram chamados a freqüentar as escolas públicas se exigia que aprendessem aquilo que ali se ensinava. $\mathrm{O}$ aluno - ente que se constitui sem consideração de gênero, condição social ou etnia - deveria assimilar estes conteúdos, sob o risco de punições durante a trajetória estipulada para isso (reprovações) e, no limite, de exclusão do mundo escolar. Consequentemente, a lógica hierarquizadora que estava, historicamente, na base da instituição escolar, inseparável da sua função avaliadora, permanecia ativa, garantindo à sociedade que aqueles que ela certificava eram 
efetivamente os 'melhores', os destacados da multidão que era chamada a passar pelas escolas.

O apêgo da instituição escolar — inclusive das escolas públicas — a essa tradição seletiva/meritocrática explica porque, apesar do acesso massificado, ela permanecia indiferente não só às diferenças sociais como também às individualidades e subjetividades dos alunos, que continuavam a ser tratados de forma impessoal, indistinta, submetidos à assimilação de determinados conteúdos - sobre os quais não lhes cabia discutir a pertinência - que deveriam, obrigatoriamente, ser incorporados sob o risco sumário de uma ação legítima e própria da escola: a reprovação. Esse modelo escolar não considerava o aluno como algo singular, não considerava seus eventuais interesses e motivações, os significados que atribuía aos saberes que the eram designados para aprender, não lhe atribuindo qualquer responsabilidade no processo de produção do conhecimento.

A predominância dessas concepções e práticas escolares pela maior parte do tempo em que as escolas existiam e serviam a contingentes numericamente pouco expressivos e o sucesso social que elas pareciam alcançar, funcionando com esses contingentes selecionados de crianças e jovens, terminou por sugerir - em conjunturas históricas marcadas por euforias democratizantes - que seus resultados poderiam ser multiplicados diante de populações mais numerosas e diversas social e culturalmente, até à sua total universalização. Como consequência dessa ilusão, torna-se cada vez mais visível aquilo que se convencionou denominar, genericamente, de fracasso ou insucesso escolar - uma forma específica de denominar uma das formas que assume a crise da escola — , resultado das exigências cognitivas, do rigor avaliativo, das reprovações impostas pela escola, tornando letra morta o projeto democratizador que estava na base da universalização da escola pública.

Ocorre que quando o contingente de 'fracassados' era pequeno porque pequeno era o universo de frequentadores da escola pública e a todos parecia absolutamente natural que a instituição escolar assim o fizesse esse 'fracasso' doía pouco em nós. Mas a sua maior visibilidade, a amplitude desse fenômeno (exatamente quando a luta pela universalização do acesso parecia estar ganha), provoca um legítimo sentimento de frustração. A escola fazia isso com muita naturalidade (afinal, isto é o que desde sempre ela 
fizera!). O 'fracasso escolar' não era uma invenção dessa escola que se massificava, pois, historicamente, o rigor avaliativo é considerado uma atribuição própria da 'boa' educação. Na história da instituição escolar, o 'fracasso' da maioria dos pretendentes a trajetórias escolares mais prolongadas é considerado como natural, intrínseco à sua função seletiva (Charlot, 2000). Mais que isso, para algumas escolas públicas (umas mais do que outras) e alguns professores (uns mais do que os outros), a reprovação massiva era uma meta, uma espécie de troféu que carregavam com orgulho, uma prova evidente do rigor e da seriedade com que desempenhavam sua função.

Assim, nas últimas décadas do século $X X$, o que vai chamar atenção e provocar maior desconforto e frustração entre todos aqueles que se empenharam pela expansão das oportunidades educacionais era a expressão quantitativa desse fracasso, maior porque maior era o contingente de novos frequentadores dos SPE. A escola pública do final do século $X X$ - agora frequentada por segmentos sociais e culturalmente extremamente diferenciados (a que se acrescenta, em países como Portugal, a experiência da imigração), bastante diversos daqueles que hegemonizaram as escolas oficiais trinta anos antes - não sabia lidar com as novas exigências postas pela diversidade dessa clientela, de seu capital cultural, de suas condições sócio-econômicas, de seus interesses e motivações diferenciados. Não sabia lidar, principalmente, com as pressões para que se transformasse de uma instituição seletiva e excludente em uma instituição inclusiva, aberta a esses novos frequentadores.

\section{As respostas, no Brasil e em Portugal, à crise da exclusão escolar}

Em Portugal, uma das proposições para o enfrentamento desse novo desafio posto à escola universalizada foi a criação dos "Territórios Educativos de Intervenção Pedagógica" (TEIP’s). Segundo Canário, Alves \& Rolo (2001), os TEIP's foram, à partida, uma tentativa de realizar, pela via da diminuição dos índices de evasão e repetência, a mística da escola transformadora. Foram propostos em atendimento a um pressuposto básico: se determinados alunos, portadores de um determinado perfil socio-econômico e cultural, não 
aprendem no ritmo e na intensidade definida ou desejada como 'normal', devem ser tratados como 'diferentes', com currículos, horários e atividades 'adaptadas', visando assegurar uma aprendizagem 'mínima' (mesmo que não fosse a 'ideal'), para evitar a possibilidade de exclusão ou abandono da escola e a eventual 'queda' dos jovens na 'marginalidade'.

As 'soluções' apontavam para a composição de classes, áreas ou territórios educativos com currículos, projetos e atividades diferenciadas dirigidas especificamente para grupos socio-econômicos diagnosticados como 'problemáticos', aos quais, por seu 'desajuste', não se recomendaria um perfil acadêmico 'clássico', apropriado unicamente às classes de alunos e a territórios sociais mais 'estáveis', capazes de atender, de maneira 'regular', às expectativas de trajetórias escolares 'normais' e, eventualmente, garantir padrões de excelência necessários à competitividade cada vez mais requerida pelas economias contemporâneas.

O cenário proposto era, indubitavelmente, inclusivo, revelador de atenção para com os contingentes populacionais que, por fatores extraescolares, não conseguiam desfrutar de oportunidades de realização de trajetórias escolares mais prolongadas. Contudo, os TEIP's, embora justificados oficialmente como solução educativa destinada a criar condições geradoras de sucesso escolar, têm como alvo não exatamente o insucesso escolar, mas a exclusão social ou, melhor dizendo, a gestão da 'questão social' (ou a 'guerra à pobreza'), dissociando "as situações de aprendizagem escolar das situações sociais em que elas se inscrevem" (Canário, Alves \& Rolo, 2001: 128), isto é, na periferia territorial e social.

Assim, na direção contrária dos desejos de fundação de um novo modelo de escola, obedecendo a uma outra lógica, com outra organização e relações internas, essas 'soluções' apontavam para uma dualidade (de escolas e/ou de classes de alunos), funcionando em paralelo, fazendo com que, apesar dos interesses declarados de "facilitar a mobilidade e a permanência no sistema aos jovens ameaçados de relegação ou exclusão", os "dispositivos de diferenciação pedagógica", reclamados para superar as resistências da instituição escolar em lidar com a diferença, terminem por sofrer uma 'tradução' que institucionaliza o estigma, com o desenvolvimento de currículos 'de segunda classe', para alunos 'de segunda classe'. 
Consequentemente, apesar de suas apregoadas boas intenções, os 'currículos alternativos' voltados para os alunos de grupos sociais adjetivados como 'problemáticos' - ou seja, que apresentavam deficiências na aprendizagem — eram, segundo Stoer (cit. por Afonso, 2000a: 33):

uma tentativa de homogeneizar por baixo de um apelo (enganador) à diversidade [...]. Na verdade, através da aparente consolidação da escola para todos, os alunos são, por um lado, colocados no exterior do currículo oficial e, por outro, são também penalizados através da crise (desta mesma escola): é que os jovens entram no mundo do trabalho oficialmente desqualificados.

No Brasil, após o alcance de índices de cobertura próximos dos 100\% da população em idade escolar, a crise da escola pública - que antes era identificada como uma crise de insuficiência de oferta - passa a ser identificada com a falta (ou a perda, para os mais nostálgicos) de qualidade no seu ensino ou, dito de outra forma, da sua incapacidade de assegurar, àqueles que a frequentavam, o domínio de um elenco mínimo de conhecimentos tomados como essenciais para a inserção dos indivíduos na vida social como adultos produtivos, autônomos, ativos, participantes.

A crença que ampara essa visão da crise da escola como uma crise de qualidade no seu ensino não põe em discussão a sua imprescindibilidade para a atribuição das qualificações e admite que o simples acesso à escola não é suficiente para assegurar essas aquisições, em função das diferenças sócio-cognitivas existentes no interior da população que as frequenta, diferenças essas que acabam por determinar os diferentes desempenhos diante das exigências da escola para assegurar o cumprimento de trajetórias escolares mais prolongadas (que, por si só, já funcionam como atestados de mérito individual).

Assim, tal como ocorreu em Portugal, a criação de dispositivos pedagógicos destinados a assegurar o sucesso escolar esteve fundada em princípios democratizantes que buscavam assegurar 0 direito à aprendizagem, fazendo com que, desde o final da década de 1980 e durante os anos 90, gestores de redes municipais e estaduais de ensino, de diferentes confissões políticas, anunciassem a disposição de implementar, nas redes de ensino de suas cidades ou estados, projetos educativos auto-denominados 'alternativos' e destinados a superar a incômoda realidade dos elevados índices de evasão e repetência? . 
Essas experiências do fim do século XX incorporavam justificativas originárias de uma literatura de base construtivista combinada com profissões de fé sobre novas funções agregadas à escola, tais como 'cultivo da cidadania', 'valorização das identidades', 'respeito às diferenças', 'desenvolvimento da convivência social', etc., ampliando bastante o âmbito das expectativas postas sobre a instituição escolar ${ }^{8}$. Esse acréscimo de expectativas tem rebatimento direto no currículo, do qual passa a ser exigido o desenvolvimento de elementos ligados à expressão de atitudes e habilidades e à incorporação de elementos culturais originários da experiência social das camadas populares (portanto, não eruditos).

Essas inovações educacionais receberam nomes distintos nos diferentes lugares em que foram implementadas ${ }^{9}$, mas todas tinham como eixo central as práticas avaliativas. Essas práticas eram secularmente fundadas unicamente na aferição de retenção dos conteúdos 'clássicos', requisito utilizado como meio de assegurar (ou não) progressão nas etapas sucessivas em que se organizam os sistemas educativos ${ }^{10}$. Os educadores brasileiros envolvidos com os princípios de uma educação escolar pública inclusiva centravam suas críticas na 'cultura da repetência' e na individualização do fracasso ensejada por essas práticas seculares de avaliação, afirmando que a escola podia e devia (re)organizar-se para garantir a apropriação dos conteúdos escolares, considerando os ritmos e limites próprios dos alunos, acatando suas motivações e respeitando o seu universo cultural de origem.

Os discursos que sustentavam o caráter socialmente mais justo da aprendizagem por ciclos - ultrapassando a formalidade das séries anuais e lutavam contra a lógica da escola meritocrática viam na padronização/homogenização dos alunos sob a forma de 'classes', ou turmas seriadas e hierarquizadas, o estabelecimento de metas indistintas de aprendizado, o que obrigava todos os alunos a ter que atingi-las no mesmo tempo previsto. A 'classe' de alunos foi historicamente concebida para lidar com o aluno 'médio'. Mas essa forma escolar que conhecemos e praticamos própria da modernidade ocidental - não é uma forma única, embora hegemônica, nem eterna de educação. É uma construção social, uma invenção. Deve ser tomada nos limites de sua origem histórica, de uma forma escolar que materializa uma determinada concepção de aprendizagem 
adequada a um tipo de sociedade na qual o tempo e os espaços de pensar são distintos e antagônicos dos tempos e espaços do agir/fazer (cf. Canário, 2004).

Esses pressupostos relativos à 'normalidade' de um tempo ou ritmo de aprendizagem estariam em desacordo com entendimentos mais progressistas ou inclusivos do processo ensino-aprendizagem (cf. Paro, 2000: 278) ${ }^{11}$. Aqui, os argumentos estavam ligados à defesa da capacidade universal de toda criança, independente de origem social ou meio cultural, de se apropriar dos conteúdos escolares definidos socialmente como necessários ${ }^{12}$. Se as crianças e jovens originários da periferia social que freqüentavam a escola pública não aprendiam os conteúdos que eram de seu encargo transmitir, é porque a instituição escolar era impermeável a uma cultura de inclusão e não rompia com a sua tradição seletiva para assegurar a aprendizagem desses alunos.

Os argumentos em favor da escola com uma organização diferenciada, com um caráter inclusivo, sempre foram, desde o início, politicamente corretos, socialmente justos e tomavam, como dado inquestionável, o caráter intrinsecamente benéfico da permanência ampliada do aluno na escola (embora apenas pelo tempo 'normal' estipulado para o cumprimento de suas etapas); admitiam, portanto, que todos os alunos podiam e deviam aprender (a la Comenius). Mas, de certa forma, atribuíam à instituição escolar a responsabilidade exclusiva pelo eventual insucesso dos alunos em trajetórias de, pelo menos, oito anos. Assim, bastaria uma mudança cultural da/na organização escolar para superar as suas práticas excludentes. Ou seja, a crise da escola, a sua ineficácia no alcance do aprendizado, poderia ser enfrentada por uma mudança 'interna', acreditandose na possibilidade de uma escola em crise resolver, a seu próprio modo, a sua própria crise.

A escola pública massificada permanece, assim, envolvida em um ciclo em que as crises se sucedem a cada nova 'solução' pedagógica que se inventa. Aqui, as medidas administrativas de promoção automática, por um lado, resultavam quantitativamente satisfatórias, aproximando o fluxo sérieidade dos parâmetros desejados. Contudo, tornava mais dramática a crise de sentido que atingia o ensino público, pois tornava "possível um aluno entrar na escola com 7 anos e sair com um diploma de $8^{\text {a }}$ série aos 14 - não tendo sequer aprendido a ler", segundo avalia Paiva (2005: 178), que completa: 
É preciso saber o que crianças e adolescentes realmente ganham com a escolarização em termos de aprendizagem - hoje mais complexa e mais necessária que no passado [...]. Isso porque estamos jogando no mercado jovens com diplomas sem os conhecimentos correspondentes e, pela primeira vez, constatamos a presença de analfabetos absolutos entre alunos com muitos anos de escolaridade (Paiva, 2005: 182-183).

\section{Algumas conclusões sem qualquer promessa de soluções}

Nenhum desses movimentos internos destinados a superar o caráter excludente da instituição escolar pode alcançar o aspecto - talvez o mais dramático - da crise da escola desde o fim do século XX: a sua impossibilidade de continuar pretendendo legitimar-se como meio de ascensão social. A expansão das matrículas, característica das últimas décadas do século XX, termina por provocar um 'excesso de certificação' (Tedesco, 1998: 45), banalizando os diplomas obtidos na educação básica e remetendo, sempre para mais adiante, aos degraus mais elevados da pirâmide educacional, a distinção social implícita no projeto de atração de toda a população à escola universalizada. Ou seja, à medida que o sistema democratiza a sua base (o ensino fundamental obrigatório), os distintivos sociais antes associados a estes níveis de escolarização desaparecem e são 'lançados adiante' para níveis superiores do sistema de ensino ${ }^{13}$ que permanecem inacessíveis à maioria da população, provocando frustrações e desencantos diante de promessas não cumpridas ${ }^{14}$.

Num contexto marcado pelo desemprego estrutural, os sistemas escolares universalizados não podem mais assegurar nem empregos, nem mobilidade social, nem acréscimos ao 'desenvolvimento', constituindo, segundo Casassus (1995: 36), o núcleo central da crise de sentido que marca os SPE desde o final do século XX e que tem um efeito devastador sobre a curva ascendente do otimismo social para com a universalização da escola (Tedesco, 1998). Essa associação entre qualificação proporcionada pela escolarização geral (isto é, básica) e oportunidades (distintivas) de um emprego não manual era possibilitada em outro momento histórico, dominado por outras formas de organização produtiva e que permitia uma euforia otimista quanto aos poderes transformadores da educação escolar (Canário, Alves \& Rolo, 2001: 15). 
Neste início de século XXI, contudo, o declínio do otimismo em torno dos poderes da escolarização universal fazem parecer que os esforços exigidos para o cumprimento de trajetórias escolares mais prolongadas são pouco compensadores, já que não asseguram a inserção no mercado de trabalho e a concretização de projetos pessoais de ascensão social (Afonso, 2000b: 105), colocando a instituição escolar diante de paradoxos, tal como o expressa Barroso (cit. por Teodoro, 2005: 11): "nunca tantos deixaram de acreditar na escola, nunca tantos a desejaram e a procuraram, nunca tantos a criticaram e nunca tantos tiveram tantas dúvidas sobre o sentido da sua mudança".

A realidade imposta por um mundo econômico transformado (e transtornado) escapa às iniciativas pontuais, localizadas, promovidas no âmbito das escolas. E os Estados Nacionais - o ente sobre o qual pesa a responsabilidade de gerir a crise dos SPE -, situados (ou sitiados) no contexto de uma economia globalizada, passam a se defrontar, no momento de definição de suas políticas educativas, com uma contradição aparentemente insolúvel. Por um lado, a escolarização universal obrigatória é apresentada como uma exigência associada à concorrência acirrada, à maior competitividade entre as nações, exigências essas que apontam para uma maior difusão da escolarização formal e de políticas de qualificação de mãode-obra. Mas, por outro lado, as características dessa economia globalizada do final do século $X X$, fundada na informatização e robótica, fazem os empregos desaparecerem, rompendo com a lógica que presidiu à expansão dos SPE no imaginário popular. Com isso, registram-se, de forma crescente, a ocorrência de problemas sociais decorrentes da impossibilidade de garantir ocupação econômica às multidões de jovens que, continuamente, finalizam a escolaridade obrigatória - e são insistentemente convencidos a frequentar as escolas públicas - e almejam inserir-se como adultos produtivos no mercado de trabalho!

Nas palavras diretas de Stoer:

com a passagem para o chamado pós-fordismo e para a época da crise do Estado de Bem-Estar, a escola para todos (des)articula-se com um sistema produtivo que desenvolve o desemprego estrutural (e outras formas de precariedade como o subemprego, o emprego clandestino, etc.), participando assim activamente no isolamento (exclusão até) de todos aqueles que não beneficiam de emprego oficial, estável, duradouro. De repente, a escola oficial 
obrigatória torna-se, ela própria, numa fonte de injustiça social. Torna-se numa fonte de injustiça social pela dupla razão de que ou deixa sair das suas portas indivíduos que não estão em condições de competir no mercado de trabalho oficial (condenando-os assim a formas variadas de desemprego) ou aprisiona os seus alunos em esquemas de formação sem fim tornando-os em estagiáriosprofissionais eternamente prontos para ingresso num mercado de trabalho ilusório (Stoer, 2001: 257. Grifo do autor).

Esse desajuste cria situações sociais que são 'devolvidas' à escola, impondo-lhes uma 'missão impossível' qual seja: apesar da sua apontada crise, ela é responsabilizada pela gestão de uma crise social presente nas periferias sócio-territoriais (expressa nas manifestações de desajuste juvenil, consumo de drogas, desajuste familiar, etc). A escola vê somada às suas funções tradicionais esperanças de que ela possa realizar uma 'ortopedia social', de servir como agência capaz de assegurar a integração, o ajuste, a estabilidade de setores sociais periféricos ou 'marginais' (Correia \& Matos, 2001). Assim, paradoxalmente, ao mesmo tempo em que se tornam cada vez mais evidentes os limites da escola para dar conta dos problemas que ela foi sendo chamada a resolver, ela é interpelada para dar solução a emergentes problemas sociais - rotulados, genericamente, como de 'exclusão social' que estão intimamente ligados à crise da sua própria universalização!

Enfim, a crise da escola pública - tanto em Portugal como no Brasil, bem como na maior parte do mundo capitalista ocidental - tem um caráter estrutural e está ligada a duas transformações simultâneas e sincrônicas: a massificação da instituição escolar - resultado de todo um conjunto de expectativas (reais ou ilusórias) quanto aos poderes transformadores da educação escolar - que se dá a par de transformações econômicas, políticas e culturais que podem ser sintetizadas sob a denominação genérica de 'globalização'. Essas últimas transformações acabam por abalar ainda mais uma instituição social que já vivia uma crise de sentido produto dos impasses que a sua massificação provocava. Assim, a crise de sentido que atinge os SPE não se origina ou é produzida unicamente no interior da instituição escolar e não pode ser destacada da crise do modelo civilizatório moderno que amparou a sua universalização.

Esse modelo escolar - apropriado a formas de produção econômica, de organização social, a utopias e regimes políticos próprios da modernidade iluminista e todos os artefatos modernos que the deram sentido - vive, 
portanto, uma crise de identidade associada às transformações aceleradas na economia mundial, na forma de atuação dos Estados Nacionais e, igualmente, nas formas de expressão sócio-cultural.

Os conteúdos disciplinares, aquilo que constitui o núcleo mais essencial da função da escola, e o 'formato' escolar historicamente consolidado para o cumprimento de sua missão histórica mostram-se obsoletos. O sentido humanista - herdado do iluminismo - , que conferia à instituição escolar legitimidade para inserir as novas gerações no mundo da cultura 'adulta' e oferecer oportunidades de mudança social, encontra-se profundamente abalado. A ocorrência de outros espaços formativos tendem a tornar os conhecimentos escolares 'clássicos' menos decisivos ou imprescindíveis e colocar sob suspeição o valor intrínseco dos certificados escolares.

No campo da transmissão cultural, as novas gerações passaram a dispor, cada vez mais, de meios de informação - que, por seu poder de insinuação, tornam-se meios de formação e de socialização — fora da instituição escolar, tais como a televisão, o cinema e a internet ${ }^{15}$. O uso de tecnologias cada vez mais complexas, as mudanças nas organizações e, principalmente, o maior poder do econômico sobre todos os outros campos provocam mudanças que avançam a uma velocidade muito maior do que as escolas são capazes de responder. A quantidade crescente de informações que circula por outros meios que não o escolar interfere nas pessoas e nas instituições, nos comportamentos e nas reflexões possíveis (ou impossibilitadas) pelo fluxo incessante e vertiginoso (em tempo real) de informações. É difícil estabelecer ou definir controles sobre este fluxo e darIhe algum sentido.

Até às últimas décadas do século $X X$, a instituição escolar não estava submetida a uma grande dúvida quanto à cultura a ser ensinada (havia uma 'alta cultura' a transmitir!). Mas o ritmo/velocidade das transformações nesse campo colocam em suspeição a continuidade e validade social desse tipo de saber. Assim, enquanto os saberes - cada vez mais especializados empregados na produção e circulação de mercadorias, no funcionamento de organizações, na regulação da vida social, na tomada de decisões políticas (cada vez mais submetidas ao pragmatismo das 'soluções técnicas') se complexificam cada vez mais, a escola permanece fincada em princípios e 
formatos próprios dos tempos que assistiram à sua universalização (Gómez, 2001: 136).

A escolarização universal e compulsória da sociedade sempre pareceu, a todos os educadores de ofício situados no campo crítico do pensamento educacional, um passo adiante da humanidade numa caminhada segura em direção a um futuro desejado de estabilidade e de predomínio da razão sobre a barbárie. Mas, diante da velocidade das transformações que se dão nas últimas décadas, os princípios que guiaram a implantação dos SPE e que permanecem em nosso imaginário como imutáveis - é preciso admitir - não tem mais razão de ser. Não estamos, afinal, lidando com uma crise da escola, mas dos modelos societais que, com ela, imaginamos construir ancorados na racionalidade moderna ou iluminista, racionalidade que nos impulsiona a acreditar que o mundo inevitavelmente segue para as direções que nossas consciências lhe dão.

No entanto, onde estão as evidências - e como nós precisamos delas para fortalecer nossos argumentos - de que a escolarização compulsória na forma como ela se deu tenha, até aqui, contribuído para construir seres humanos mais humanos, extirpar as guerras, os saques neo-coloniais, eliminar a fome, etc. ${ }^{16}$ ? Sabemos, isso sim, principalmente com Foucault, como a instituição escolar tem participado do movimento de disciplinamento, enquadramento, submissão, hierarquização, normatização, repressão (a lista aqui, poderia ser muito longa) da infância e da juventude na direção contrária do suposto aperfeiçoamento da 'natureza humana'.

Talvez seja necessário considerar a impossibilidade de uma escola diferente da sociedade na qual ela está encravada. E, se assim fôr, nossas esperanças de uma escola transformadora como um enclave no interior de uma sociedade 'repressora' são uma enorme ingenuidade ou um altar onde depositamos nossas poucas esperanças num mundo que parece ter ruído aos nossos pés.

Autores como Sousa Santos (2001) têm-se arriscado a lançar proposições, a desenhar cenários de futuros com pretensões de constituir-se em alternativas ao vazio desses tempos pós-modernos. Mas manifestações como essas são, além do seu alcance limitado, uma possibilidade acessível a um número muito restrito de autores. Cabe-nos, portanto, o compromisso senão com o anúncio - com a crítica, com a denúncia, com o inconformismo 
diante das repetidas 'soluções internas' à escola que se recusam a pôr em discussão as muitas e diferentes determinações que a envolvem.

A construção de caminhos alternativos à crise da escola não é tarefa de alguns poucos, nem dos iluminados pelas descobertas da investigação científica nem dos detentores do poder institucional que se reservam o direito (afinal, ganharam as eleições!) de definir os 'interesses' da maioria. Porque não estamos diante de um problema localizado, específico, um problema 'técnico' que pode ter uma solução cirúrgica. A escola não faz sentido fora de projetos sociais. Se faltam estes, a escola fica vazia de sentido, fica em crise. Não nos faltam projetos para as escolas. Nos faltam projetos para a sociedade.

Este texto não pretende purgar as culpas pelo fato das utopias da modernidade não terem dado certo. Nem pretende (ah!, se ele pudesse, que poder teria!) prescrever as saídas. Mas não tem medo de enfrentar "a derrocada das velhas certezas em torno da educação" (Enguita, 2004). Sem defender, a princípio, nem as teses da desescolarização da sociedade nem a sacralização da instituição escolar. Sem dogmas ${ }^{17}$. E afirma que as formas de se pensar a escola - nos marcos ou nos limites do contexto histórico no qual ela se afirmou como instituição social estruturante das sociedades modernas, com e a partir da construção dos Estados-Nação - estão sendo tragadas pela crise das sociedades paridas pela modernidade.

Por fim, pensamos que, vista sob a ótica crítica dos estudos históricos, as coisas não parecem ser tão difíceis assim, pois, afinal, a escola é uma instituição bastante antiga e não foi sempre tal como a conhecemos hoje. Sendo assim, não há porque duvidar que ela possa sobreviver assumindo outras formas e outras finalidades, de acordo com outros projetos sociais. Mais difícil, como sempre, é imaginar a que tipo de sociedade ela deverá servir.

\section{Notas}

1 Este texto é um primeiro produto de um estágio acadêmico na Faculdade de Psicologia e de Ciências da Educação da Universidade do Porto (FPCE/UP).

2 A profusão de títulos, produzidos por respeitados autores, não deixa dúvidas: Vorraber, 2003 (A Escola tem futuro?); Enguita, 2004 (Educar em tempos incertos); Sacristán, 2001 (Poderes instáveis em educação), são apenas alguns dos exemplos mais expressivos. 
3 Empregamos esclarecidos em referência à intelectualidade brasileira que, desde o final do século XIX, empenhava-se em 'ilustrar' o país, em 'iluminá-lo' pela ciência e pela cultura na busca de uma nação transformada (Barros, 1986: 9).

4 É o que se pode depreender da afirmação de Ghanem: "Assegurar o acesso universal aos serviços escolares é a primeira condição fundamental para uma relação adequada entre educação escolar e democracia. Qualquer alegação restritiva contra esse esforço, ainda que baseada em sérias preocupações com processos pedagógicos, assumirá necessariamente um caráter elitista, discriminatório, por conseguinte antidemocrático" (2004: 90).

5 Tanto no Brasil quanto em Portugal, o período de euforia com o 'progresso' urbanoindustrial são as décadas de 1950/60.

6 Essa afirmação encontra amplo amparo simultaneamente na bibliografia brasileira e portuguesa.

7 Segundo Paiva (2005), muitas dessas experiências tinham como real intenção apenas a "correção do fluxo do sistema" ou a "eliminação dos desperdícios" associados aos números tabulados das reprovações escolares. Cf. igualmente Barreto \& Mitrulis, 2001 e Gomes, 2004.

8 A incorporação pela escola de preocupações mais apuradas com os aspectos cognitivos da aprendizagem, a introdução de métodos 'ativos' de ensino ou a consideração da motivação do aluno como ponto de partida para a organização do processo de ensino-aprendizagem não são novidades na história da educação brasileira. Mas essas inovações pedagógicas tinham um sentido de aperfeiçoamento da função da escola, sem colocar em questão aquilo que seria o seu sentido dominante.

9 Escola Candanga em Brasília, Escola Cabana em Belém do Pará, Escola Plural em Belo Horizonte, Minas Gerais, por exemplo.

10 Essas etapas não possuem um caráter meramente temporal, ligadas à faixa etária dos alunos, mas implica julgamentos sobre as capacidades cognitivas demonstradas pelos alunos para cumpri-las, uma após a outra.

11 No limite, tais discursos afirmavam que os alunos não aprendiam porque os professores não sabiam ensinar ou não se preocupavam com eles e que a instituição escolar seguia sendo indiferente ao futuro escolar das camadas populares, o que exigiria da escola uma profunda mudança cultural para reverter esse sentido (Paro, 2000). E, acrescentaríamos nós, sem necessidade de 'sair' da escola; tratar o problema como uma questão 'interna'.

12 Cabe assinalar, oportunamente, que termos como 'aprendizagem bem feita' ou 'desempenho escolar aceitável' são tomados como dados, como se fossem autoexplicativos. Cf. especialmente Demo, 1998.

13 Bourdieu (1989) refere-se a um outro mecanismo de preservação de seletividade, mesmo quando o sistema se 'democratiza': a exibição de diplomas conferidos pelas 'escolas nobres', as mais seletivas/exigentes e que asseguram aos seus portadores distintivos ou qualificativos que as escolas 'banais' não podem assegurar.

14 É curioso observar que, apesar disso, defende-se a universalização do acesso ao ensino superior. Cf. Enguita (2004: 33). 
15 É "uma vida social presidida pelos intercâmbios à distância, pela supressão das barreiras temporais e pelas fronteiras espaciais" (Gómez, 2001: 12).

16 Não há como confundir, aqui, a contribuição libertária de Paulo Freire. O projeto educativo freireano não cabe no modelo escolar dominante, modelo escolar adequado a outro projeto político.

17 A este título, vale pensar se a escola soviética, a escola da 'nova sociedade', ou mesmo a escola cubana ou, ainda, da Nicarágua no período Sandinista, momentos de tantas promessas de mudança, eram substancialmente diferentes do modelo 'burguês' (ou, quem sabe, do jesuítico) que se universalizou. Bettelheim, comentando os anos imediatamente seguintes à tomada do poder na Rússia pelos bolcheviques, afirma que os 'aparelhos escolares' praticamente não tinham sofrido transformações e, mesmo com a consolidação da nova ordem soviética, mesmo com a extinção das escolas privadas, o 'aparelho escolar' continuava sendo burguês, "pela maneira como ensinam" e "pelo tipo de relação entre teoria e prática que ali é privilegiado" (1979: 156). Talvez sejamos obrigados a admitir que a única mudança mais visível tenha sido a retirada dos crucifixos na parede e que as mudanças tenham se dado, apenas, nos discursos sobre a escola (cf. Carvalho, 2005).

\section{Referências}

AFONSO, Almerindo J. (2000a) Políticas educativas em Portugal (1985-2000): a reforma global, o pacto educativo e os reajustamentos neo-reformistas. In A. M. Catani \& R. P. Oliveira (Orgs.), Reformas Educacionais em Portugal e no Brasil. Belo Horizonte: Autêntica.

AFONSO, Almerindo J. (2000b). Avaliação Educacional: Regulação e Emancipação. São Paulo: Cortez.

BARRETO, Elba S. S. \& MITRULIS, Eleny (2001). Trajetória e desafios dos ciclos escolares no país. Revista Estudos Avançados, nำ42, São Paulo: USP.

BARROS, Roque S. M. de (1986). A Ilustração Brasileira e a Idéia de Universidade. São Paulo: Convívio/EDUSP.

BETTELHEIM, Charles (1979). A Luta de Classes na União Soviética: Primeiro Período (1917-1923). Rio de Janeiro: Paz e Terra.

BOURDIEU, Pierre (1989). La Noblesse d'État (Grandes Écoles et Esprit de Corps). Paris: Ed. de Minuit.

BURBULES, Nicholas \& TORRES, Carlos A. (2004). Globalização e educação: uma introdução. In N. Burbules \& C. A. Torres (Orgs.), Globalização e Educação: Perspectivas Críticas. Porto Alegre: ARTMED.

CANÁRIO, Rui; ALVES, Natália \& ROLO, Clara (2001). Escola e Exclusão Social (Para uma Análise Crítica da Política TEIP). Lisboa: Instituto de Inovação Educacional/EDUCA.

CANÁRIO, Rui (Org.) (2004). Escola da Ponte: Defender a Escola Pública. Porto: Profedições. 
CARVALHO, Marta M. C. (2005). História e historiografia da escola pública no Brasil: algumas considerações em torno de um programa de investigação. In J. C. Lombardi; D. Savani \& M. I. M. Nascimento (Orgs.), A Escola Pública no Brasil: História e Historiografia. Campinas/SP: Autores Associados/HISTEDBR.

CASASSUS, Juan (1995). As Tarefas da Educação. São Paulo: Cortes.

CHARLOT, Bernard (2000). Da Relação com o Saber: Elementos para uma Teoria. Porto Alegre: ARTMED.

CORREIA, José A.; CORTESÃO, Luiza \& STOER, Stephen (Orgs.) (2001). Transnacionalização da Educação: da Crise da Educação à "Educação da Crise". Porto: Afrontamento.

CORREIA, José A. \& MATOS, Manuel (2001). Da crise da escola ao escolocentrismo. In J. A. Correia; L. Cortesão \& S. Stoer (Orgs.), Transnacionalização da Educação: da Crise da Educação à "Educação da Crise". Porto: Afrontamento.

CORREIA, José A. (2006). O científico e o político na educação contemporânea. Texto não publicado.

CORTESÃO, Luiza (2000). Ser Professor: um Ofício em Extinção? Porto: Afrontamento.

CORTESÃO, Luiza (2001). Guliver entre gigantes: na tensão entre estrutura e agência, que significados para a educação? In J. A. Correia; L. Cortesão \& S. Stoer (Orgs.), Transnacionalização da Educação: da Crise da Educação à "Educação em Crise". Porto: Afrontamento.

DEMO, Pedro (1998). Promoção automática e capitulação da escola. Revista Ensaio: Avaliação de Políticas Públicas em Educação, no 19.

ENGUITA, Mariano F. (2004). Educar em Tempos Incertos. Porto Alegre: ARTMED.

GHANEM, Elie (2004). Educação Escolar e Democracia no Brasil. Belo Horizonte: Autêntica.

GIDDENS, Anthony (1995). As Consequências da Modernidade. Oeiras: Celta.

GOMES, Cândido A. (2004). Quinze anos de ciclos no ensino fundamental: um balanço das pesquisas sobre a sua implantação. Revista Brasileira de Educação, № 25.

GÓMEZ, Angel Pérez (2001). A Cultura Escolar na Sociedade Neoliberal. Porto Alegre: Artmed.

HOBSBAWM, Eric (1998). A Questão do Nacionalismo. Nações e Nacionalismo desde 1780 - Programa, Mito, Realidade. Lisboa: Terramar.

LOMBARDI, José C.; SAVIANI, Dermeval \& NASCIMENTO, Maria Isabel M. (Orgs.) (2005). A Escola Pública no Brasil: História e Historiografia. Campinas/SP: Autores Associados/HISTEDBR.

MANACORDA, Mário A. (1989). História da Educação. São Paulo: Cortez.

PAIVA, Vanilda (2005). Escola pública brasileira na atualidade: lições da história. In J. C. Lombardi; D. Saviani \& M. I. M. Nascimento (Orgs.), A Escola Pública no Brasil: História e Historiografia. Campinas/SP: Autores Associados/HISTEDBR.

PARO, Vitor H. (2000). Porque os professores reprovam: resultados preliminares de uma pesquisa. Revista Ensaio: Avaliação e Políticas Públicas em Educação, nº 28. 
SACRISTÁN, José G. (1999). Poderes Instáveis em Educação. Porto Alegre: ARTMED.

SACRISTÁN, José G. (2001). A Educação Obrigatória: seu Sentido Educativo e Social. Porto Alegre: Artes Médicas.

SILVA, Geraldo B. (1959). Introdução à Crítica do Ensino Secundário. Rio de Janeiro: MEC/CADES.

SILVA, Tomaz T. da (1993). Teoria Educacional Crítica em Tempos Pós-modernos. Porto Alegre: Artes Médicas.

SOUSA SANTOS, Boaventura (org.) (2001). Globalização: Fatalidade ou Utopia? Porto: Afrontamento.

SOUSA SANTOS, Boaventura (2003). Democratizar a Democracia: os Caminhos da Democracia Participativa. Rio de Janeiro: Civilização Brasileira.

SPÓSITO, Marília P. (1984). O Povo Vai à Escola (A Luta Popular pela Expansão do Ensino Público em São Paulo). São Paulo: Loyola.

STOER, Stephen (2001). Desocultando o voo das andorinhas: educação inter/multicultural crítica como movimento social. In J. A. Correia; L. Cortesão \& S. Stoer (Orgs.), Transnacionalização da Educação: da Crise da Educação à "Educação da Crise". Porto: Afrontamento, pp. 245-275.

TEDESCO, Juan C. (1998). O Novo Pacto Educativo (Educação, Competitividade e Cidadania na Sociedade Moderna). São Paulo: Ática.

TEODORO, António (1994). Política Educativa em Portugal. Educação, Desenvolvimento e Participação Política dos Professores. Venda Nova: Bertrand.

TEODORO, António (2005). Novos modos de regulação transnacional de políticas educativas. In A. Teodoro \& C. A. Torres (Orgs.), Educação e Utopia: Perspectivas para o séc. XXI. Porto: Afrontamento.

VASCONCELOS. Celso dos S. (2001). Para Onde Vai o Professor? Resgate do Professor como Sujeito de Transformação. São Paulo: Libertad.

VORRABER, Mariza (2003). A Escola tem futuro? Rio de Janeiro: DP\&A. 
SCHOOL CRISIS OR CRISIS AT SCHOOL? AN ANALYSIS OF THE SENSE OF CRISIS OF THE PUBLIC SYSTEMS IN THE FRAMEWORK OF THE COMPULSORY EDUCATION

Abstract

This study discusses the meaning that are ascribed to the crisis of public (state) schools of compulsory attendance in the educational critical literature published since the last decades of the 20th century, both in Brazil and Portugal. It lists the optimistc expectations that impelled the massification of schooling after the Second World War and compares them with the impasses that the public systems of education are confronting, at the beginning of the $21^{\circ}$ century, and which are largely due to the unfulfilled promises of modernity. It also deals with the impact of the changes of globalised cultures and economies, multicultural societies, accelerated information, and Nation-States deflated of their historical functions in the configuration of that crisis; it deals as well with the different estrategies that have been designed, both in Brazil and in Portugal, in order to overcome this crisis.

Keywords

Public education; School smash; History of education; Public school 


\section{CRISE DE L'ÉCOLE OU À L'ÉCOLE ? UNE ANALYSE DE LA CRISE DE SENS DES SYSTĖMES D'ENSEIGNEMENTS PUBLICS OBLIGATOIRE}

Résumé

Cette étude vise à lever les raisons qui sont attribuées à la crise de l'école publique de fréquence obligatoire dans la littérature éducationnelle critique, produite depuis la fin du XXème siècle au Brésil et au Portugal. Souligne les expectatives optimistes qui ont contribué à donner un nouveau souffle après la deuxième guerre mondiale - a la massification de l'institution écolière, se confrontant aux impasses auxquelles se heurtent les systèmes publics d'enseignement, en ce début de XXlème siècle, face aux promesses de la modernité qui ne sont pas respectées. Aborde encore, l'impacte des transformations d'économies et cultures globalisées, de sociétés multiculturelles, d'information accélérée et des états - nations vidées de ses fonctions historiques pour la configuration de cette crise et les différents dispositifs qui sont mis en ouvre, au Brésil et au Portugal, destinés à l'erradiquer.

Mots-clé

Enseignement publique; Echeque scolaire; Histoire de l'education; École puplique

Recebido em Junho, 2006

Aceite para publicação em Março, 2007 